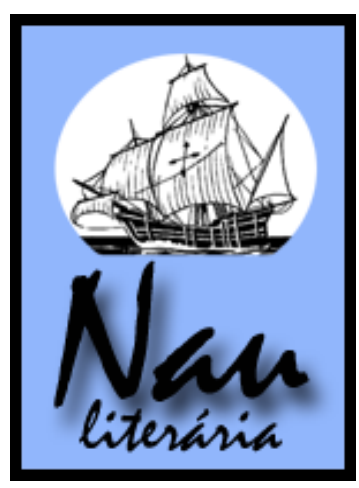

\title{
As várias faces da poesia de Hilda Hilst
}

Edson Costa Duarte*

\begin{abstract}
Resumo: Este ensaio pretende dar uma visão geral da poesia da escritora Hilda Hilst. Ressaltamos como num primeiro momento a produção poética da escritora está ligada à tradição, repetindo seus lugarescomuns da tradição literária; e aos poucos, Hilda dá novas formas a eles, novos usos. Com o passar do tempo sua poesia ficará mais complexa, aparecendo a metalinguagem como modo de questionar própria validade do real poético.
\end{abstract}

Palavras-chave: produção poética, tradição. Hilda Hilst, metalinguagem.
Summary: This essay aims to give an overview of Hilda Hilst's poetry. We emphasize how at first time the poetic production of the writer is linked to tradition, repeating his commonplaces of literary tradition; and gradually, Hilda gives them new forms, new uses. Over time his poetry will become more complex, appearing as the metalanguage mode of questioning the very validity poetic real.

Keywords: poetic production, tradition. Hilda Hilst, metalanguage.

O trabalho literário da escritora brasileira Hilda Hilst (Jaú / SP, 1930 - Campinas / SP, 2004) é um dos mais importantes da literatura brasileira, equiparando-se, para alguns críticos, aos de Guimarães Rosa e Clarice Lispector. Ao longo de cerca de cinquenta anos, Hilst escreveu uma obra multifacetada e singular. De 1950 até 1966 dedicou-se somente à poesia, depois ao teatro, tendo feito oito peças entre os anos de 1967 e 1969, e, por fim, também à ficção, quando publicou Fluxo-floema, em 1970, com prefácio do importante crítico alemão, radicado no Brasil, Anatol Rosenfeld. Deste ano até o fim de sua vida, a escritora alterna a publicação de livros de prosa e poesia e um de crônicas, escritas, entre 1992 e 1995, para o jornal Correio popular, de Campinas / São Paulo, e nunca mais escreve teatro, embora tenha inserido vários trechos dramáticos em seus livros de prosa.

Durante toda sua carreira literária, Hilst publicou 16 livros de poemas. O primeiro deles, Presságio, em 1950, e o último em 1995, intitulado Cantares do sem nome e de partidas. Três são os temas mais recorrentes na poesia hilstiana, que muitas vezes aparecem amalgamados e vinculados à ideia do tempo: o amor, a morte e Deus. Esses temas são revisitados pela escritora ao longo de sua trajetória poética, ganhando diferentes nuanças, novas perspectivas de entendimento.

\footnotetext{
* Doutor pela Universidade Federal de Santa Catarina (2002 a 2006). Pós-doutorado pela Unicamp, Instituto de Filosofia e Ciências Humanas, departamento de História (2007 a 2009).
} 
Desde o início de sua carreira, a linguagem poética de Hilst foi se construindo a partir de um intenso diálogo com a tradição literária. Com o passar dos anos, sua dicção poética aos poucos revigora e reescreve o passado, seja pela derrisão, seja pela reinserção de formas e temas da tradição em vozes dissonantes que se mesclam nos poemas. Hilst tem consciência de que o poeta é uma persona, uma máscara que atua no poema, e ao usar formas poéticas, metáforas e temas já usados por outros poetas, ela assim o faz no intuito de que esses recursos criem uma empatia, um pacto de confidência com o leitor. O desejo de Hilst é retomar a dicção elevada da poesia brasileira, deixada de lado depois do modernismo.

Como comenta o crítico Alcir Pécora, Hilst faz isso de duas maneiras, a primeira é a da poesia órfica de matriz rilkeana, a segunda é o uso dos modelos das cantigas medievais portuguesas, como se percebe nitidamente em Roteiro do silêncio (1959) e Trovas de muito amor para um amado senhor (1960). Neste último caso, quando finge ser a amiga ou a pastora quinhentista, que aparece nos cenários amorosos das cantigas, muitas vezes algo soa dissonante, pois a máscara que a escritora utiliza difere da amada medieval, que fala de seu sofrimento (coyta) de amor, causado pela distância do amado. Em Hilst, embora ela use a forma e muitos lugares-comuns das cantigas, muitas vezes alguma coisa não se encaixa ao teatro do amor que aparece nestes textos. Como, por exemplo, quando aparece a ironia, que desfaz a ideia de um amor suave e ameno. Nas palavras de Pécora: “A persona lírica põe-se, então, do outro lado da fronteira que abriga as moças donzelas e a vida burguesa do amigo, com seus filhos lindos e sua mulher, legítima e acinturada.” (Pécora 2002; p. 8)

No fim das contas, num primeiro momento de sua produção poética, Hilst muitas vezes coloca às claras o próprio jogo cênico, que existe há séculos, e que foi usado por muitos poetas. Sobre a lírica trovadoresca, por exemplo, Angelica Rieger afirma que o poeta é o criador da domna amada e do amante cortês que aparecem no poema. Esta mulher a quem o poeta direciona o poema tem uma relação puramente poética com o amante cortês. A identificação, que o trovador deseja, entre o poeta que ama e entre a mulher e a domna amada se situa fora do texto, no auditório que desempenha um papel primordial no trovadorismo. Desta forma, sempre dependendo deste auditório que toma o papel de julgador, o trovador aproveita-se do contato direto com seu público para criar uma atmosfera de cumplicidade, uma conivência comparável àquela que existe entre o ator e seu público: sendo assim, o poeta é ao mesmo tempo ator e diretor de uma intriga amorosa na qual ele representa o papel principal, o do amante cortês (Rieger 1983)

Em seus primeiros livros Hilda Hilst recoloca em cena este caráter oral da poesia, faz uma poesia mais palatável, com uma linguagem simples, sendo mais facilmente entendida 
pelo leitor. Nos poemas de Hilst escritos até o livro Poesia (1959 - 1967), a escritora valeu-se reiteradamente deste expediente no intuito de cair no gosto do público; isto, aliás, é o que almeja todo poeta, ou como declara Hilda: "Quero permanecer no coração do outro."

Numa entrevista concedida a Braulio Pedroso, em 1961, Hilst afirma: “Eu diria que os versos se sucedem quase que por magia. O que representa esforço, sem dúvida, é conseguir tecnicamente o que já foi captado sensorialmente. "i Esta busca se adensará ao longo dos anos, e só depois de muito trabalho é que, aos poucos, a escritora conseguirá ajustar perfeitamente a técnica da poesia à expressão do sentimento. Em seus primeiros livros, a poesia hilstiana é indistinta da de outros poetas que escreviam na época, não acrescentando nada de novo em termos de valor poético, tem pouco vigor e inovação. Nesta mesma entrevista a Pedroso, falando de Ode fragmentária (1961), Hilst comenta que em seu livro há a busca de compreender o homem, em sua condição ambivalente, e sua ânsia que o leva à eterna procura da beleza, da perfeição, e ressalta que escolheu a imagem da rosa, tantas vezes usada por outros poetas, como símbolo de um ideal mais alto, afirmando ter feito isto sem nenhuma originalidade. Procurando exemplificar o que afirma, a escritora cita um trecho de um poema do livro: "Hei de buscar a rosa / - A dos altares - / E sinto graça nos pés / Leveza nos andares. ,

A contradição flagrante da poesia primeira de Hilst é justamente o fato de a escritora conseguir um maior equilíbrio entre a ideia e sua expressão (de forma a que não haja o nítido entrechoque entre uma ideia complexa e uma resolução estética ainda pouco apurada) somente a partir de 1974, quando publica Júbilo memória noviciado da paixão. Embora anos antes ela tenha escrito alguns dos poemas que constam deste livro, como se pode verificar na bibliografia no fim de Fluxo-floema (1970), em que aparece "Ode descontínua e remota para flauta e oboé" - 1969 - inédito, Hilst passará 7 anos sem publicar um livro de poesia.

O movimento de uma leitura horizontal, cronológica, da obra poética da escritora demonstra como ela mantém, como já foi dito, um intenso diálogo com a tradição literária, muitas vezes paródico e irônico. A este movimento, oponho um outro, agora vertical, de intensidade e aprofundamento da dicção poética, que pode ser percebido quando se lê a poesia que Hilst produziu a partir de 1974.

Em 1981, foi atribuído à escritora, pelo conjunto de sua obra, o Grande Prêmio da APCA. Num texto em que faz um balanço da obra de Hilst, um leitor atento como Leo Gilson Ribeiro (mesmo que se saiba dos exageros de muitos de seus textos), ao falar do livro Poesia (1959/1979), faz a justa observação de que “ [...] a grande poesia hilstiana só alça voo mesmo a partir do seu longo silêncio, de sete anos, entre 1967 e 1974. "'ii O crítico ainda 
afirma que antes de 1974 a obra poética de Hilst nada tem de excepcional. Demarcada esta data em que a poesia de Hilst "alça voo", veremos que há um movimento de verticalidade da poesia hilstiana, que se deve ao assentamento de uma linguagem poética que ganha corpo e forma, pelo definitivo estabelecimento de marcas estilísticas que singularizam o estilo da poeta. A obra poética posterior de Hilst (1974 - 1995) será feita de verticalizações e desdobramentos temáticos e estilísticos progressivamente mais vigorosos e vertiginosos. Para tanto, muitas vezes a escritora se vale de frases poéticas desestruturantes, de uma linguagem marcada pelas volutas, redemoinhos do pensamento, descentramentos da escrita.

O que se percebe, então, é que com o decorrer dos anos, Hilst vai elaborando sua poesia no trânsito entre a clareza e a opacidade, uma poética que passa a não suportar a síntese, ou cuja síntese passa a se fazer no terreno da "movência conceitual", termo que emprego para designar este lugar discursivo onde o próprio discurso volta-se sobre si mesmo, relativizando-se e revitalizando-se, ao distanciar-se de si mesmo e se questionar. Este viés metalinguístico da poesia hilstiana, marca o lugar de onde a poeta fala, o lugar da metamorfose, da teatralidade, colocada às claras, do fazer artístico. Hilst faz uma poesia que não tende à síntese, à formulação de um quadro estável do que venha a ser isto do real poético; mas que prescreve a validade, a veracidade e a potencialidade deste real poético frente ao próprio real. "Um poema entre-muros / Quer nascer, de carne jubilosa / E longo corpo escuro. Pergunto-me / Se a perfeição não seria o não dizer / E deixar aquietadas as palavras / Nos noturnos desvãos. Um poema pulsante / Ainda que imperfeito quer nascer." A escritora almeja fazer uma poesia que não representa o real, mas que o apresenta, que dá forma a um real possível. Desta origem borbulhante, larval e informe é que Hilst representa possíveis estados de alma, anseia fazer uma poesia, por meio daquilo que excede a significação das palavras, sempre no trânsito entre o dizível e o indizível.

Se pensarmos em Júbilo memória noviciado da paixão, veremos que ele foi publicado num momento em que Hilst acabara de escrever suas oito peças de teatro e estava escrevendo prosa. O livro deve ser entendido dentro deste contexto, visto que neste momento de sua obra a escritora começa a quebrar a noção dos gêneros. O dramático migra para a poesia, esta para o drama, este para a prosa. Percebemos que ocorre o assentamento, o decantar de recursos estilísticos que vinham sendo usados pela escritora. Neste momento, a linguagem poética da escritora já tem um corpo bastante estruturado, e a partir de então ela investirá suas forças para um aprofundamento e proliferação das tensões significativas conseguidas até então. Para tanto, investe numa linguagem cada mais trabalhada e precisa, num ritmo cada vez mais cortado ou alongado, na invenção de palavras etc. Percebemos que a escritora faz um desbaste 
de sua linguagem poética, deixando os recursos estilísticos que ela julga mais importantes e eficazes, às vezes dando-lhes uma nova função, revitalizando os seus efeitos. Além disto, Hilst incorporará novos recursos a seu fazer poético, que darão um remate final a seu modo de fazer poesia, marcando definitivamente o aparecimento de uma linguagem singular, original, o seu estilo. É um momento de ajustes e de refinamento da criação poética. Júbilo memória noviciado da paixão é um livro mais denso e "roteirizado", nele Hilst se apoia a maioria dos poemas num único fio temático, e a partir dele desenrola teias ou centros significativos, em torno dos quais todos os poemas orbitam, ao mesmo tempo que os eles guardam sua autonomia, dando-nos um roteiro de reflexões sobre um mesmo tema.

O que mais nos chama atenção na obra poética de Hilst deste momento (1974-1995) é o grau de organicidade que ela contém. Essa ideia de um todo coeso deve-se ao fato de que a poeta segue um roteiro no seu fazer poético. Sendo assim, neste período, em cada livro de poemas da autora há um tema que serve como espinha dorsal, como viga mestra para suas reflexões acerca de si mesma em contato com o mundo que a rodeia. Esse tema irá se repetir nos vários poemas, de modo a permear toda a compreensão do mundo caótico e desordenado, no qual a poeta se vê como um ser repleto de dúvidas. Dessa maneira é que Hilst poderá ter uma ordenação necessária ao pensamento para que possa conter e organizar toda a profusão de questionamentos a que está sujeita. É precisamente esse processo que lhe possibilita, então, um maior aprofundamento das ramificações que um mesmo tema pode sugerir. Assim, encontramos em cada livro de poesia de Hilda Hilst um tema básico de reflexão que toma várias nuanças e se repete exaustivamente ao longo dos poemas.

Nos poemas de Júblio memória, noviciado da paixão (1974), o centro de atração temático é o amor não-realizado. A poeta intenta dialogar com o seu amado, que despreza seu amor. O potencial amante se metamorfoseia, sendo chamado por vários nomes - Túlio, Ricardo, Dionísio -, que simbolizam os vários modos de figuração do afeto, no presente caso, do amor. Em Da morte. Odes mínimas (1980) há a preocupação com o redimensionamento da vida por meio da reflexão sobre a morte, o impossível instante do encontro com o desconhecido. Em Cantares de perda e predileção (1983), tem-se uma doída reflexão sobre o sentimento ambíguo e contraditório da paixão, vista sobre viés do amálgama paradoxal entre o ódio e o amor, numa perspectiva de um ser que se sabe, pelo desejo, inteiro presa do outro ser. Em Poemas malditos gozosos e devotos (1984), a poeta dialoga com um Deus de quem ela desconfia, pois este Deus é cruel, é O Deus do Novo Testamento, que manda seu filho padecer um sofrimento sobre-humano. Em Sobre a tua grande face (1986) há a tentativa da nomeação de Deus. O DESEJADO, Cara Escura, Sem Nome, estes são alguns de seus nomes 
utilizados no livro. Nestes poemas, há a busca da dimensão humana, da pequenez do homem diante do possível contato com a divindade, e sua incapacidade de nomear o Absoluto e, num movimento contrário, a elevação do humano em direção ao divino, que se é visto como corpórea fantasia do humano. Em Amavisse (1989), a principal reflexão é sobre a relação do homem com a passagem do tempo, e sobre como se dá a consciência humana do real, a poeta se vê diante da consciência da existência do outro, objeto de adoração, de amor e de estranheza, e a tentativa de comungar com essa estranheza. O título do livro, em latim, quer dizer "ter um dia amado", o que nos remete à nostalgia, à rememoração de um estado passional fixado no tempo como matéria de vida e reconhecimento. Em Alcoólicas (1990), tem-se a celebração da vida, a busca de sua dignificação e sentido. O escorrer do tempo (metaforizado na bebida, no líquido) como possibilidade para a transformação do homem na busca do entendimento de sua existência. Em "Da noite" e "Do desejo" (partes inéditas publicadas no livro Do desejo, 1992), ${ }^{\vee}$ tem-se o itinerário da busca de entender e nomear a intensidade do desejo, em seu viés físico e metafísico. A epígrafe do livro diz: "Quem és? Perguntei ao desejo. / Respondeu: lava. Depois pó. Depois nada." ${ }^{\text {vi }}$ Em Cantares do sem nome e de partidas (1995), último livro de poesia que Hilst publicou, encontramos a nostalgia do amor sonhado que toma a cena dramática dos poemas, refletindo a potência deste recordar como ato criador de uma realidade poética em que realidade e sonho se mesclam na apresentação ficcional do momento das perdas, das partidas e da dissolvência do sujeito no instante da intensidade do sentimento.

Se a organicidade é uma das marcas da obra poética de Hilst deste período, outra é uma busca intensa de comunicação, de embate dramático do sujeito com seu objeto de reflexão. Será justamente essa busca um dos pontos mais importantes de diferenciação de sua poesia. O recurso mais insistentemente utilizado pela escritora será um intenso e tenso diálogo com um outro que às vezes é humano, mas na maioria dos casos é uma abstração, um duplo da própria consciência da poeta. Deste modo é que a ideia de Deus, da Morte, da Vida, do Desejo, da Paixão, do Amor se personificarão em possíveis interlocutores da poeta. A importância deste recurso é que permite à escritora uma apreensão mais profunda e multifacetada de suas experiências, uma comunicação mais intensa e produtiva, um embate mais direto com os conceitos e sentimentos mais abstratos do ser humano.

Neste período da obra poética de Hilst (1974-1995), concomitante a esse fazer orgânico textual e a essa busca de dialogação, assistimos a um progressivo aprofundar das questões poéticas e estéticas visitadas anteriormente pela autora. Passamos, neste movimento, de uma menor tensão e de uma maior clareza metafórica para uma linguagem mais tensa e 
dilacerada, para uma opacidade referencial. Os temas de que falamos que aparecem reiteradamente nos poemas hilstianos (a amor, a morte, deus), serão ajustados a novas representações, geralmente ligadas ao tempo, um tempo múltiplo e mutante, indefinível por sua própria natureza de conceito que se metamorfoseia e se agrega a tantos outros.

Ao se debruçar sobre o tempo, Hilst fala sobre a experiência humana da dissolvência do corpo. Percebemos que o tempo passa a ser o principal personagem, conceito, de que a poesia hilstiana se ocupará, sendo ao mesmo tempo índice de uma revolta e da figuração do fluir da existência. Revolta contra a perecibilidade do corpo, e fingimento teatral de figurar nesta revolta um ar de superioridade, de resignação diante da consciência de não se estar grudado ao tempo. Falamos de um teatro bem sucedido, de um ser que sofre ao pensar na passagem do tempo em seu corpo, mas também de um ser que se coloca, ironicamente, além desta consciência, observando de fora sua impotência diante do fato de se saber perecível: " $E$ se eu ficasse eterna?/ Demonstrável / Axioma de pedra"? ${ }^{v i i}$ Aqui, vemos a visada racionalizante que pode ser notada ou pelo viés metalinguístico mais aparente do texto, ou por uma espécie de humor refinado, de ironia cáustica que se refere ao entendimento do real poético como uma construção ficcional que seria mais verdadeira que o próprio real, à medida que potencializa, pela exatidão da palavra, a encenação dramática do próprio real.

As marcas temporais indicam o lugar discursivo em que o sujeito aparece, como um evento, lugar em que se abre uma fenda na qual se instaura a voz do poeta. Deste lugar discursivo é que o sujeito revela sua apreensão do mundo, expondo-se ao tempo da linguagem a partir da figuração, da encenação dos afetos (emoções, sentimentos, sensações). Na obra poética de Hilst a experimentação do tempo revela-se paradoxal, porque carrega em si uma sensualidade quase sexual de se estar vivo indissoluvelmente ligada à consciência de se saber morrendo em vida. Na fusão entre a representação estética destes dois tempos: o tempo longo e moroso da dilatação e o tempo da fugacidade do instante, Hilst interporá seu texto poético como uma ramificação de questões derivadas destas experiências do(s) tempo(s). Para pensar o amor, o desejo, a vida e a morte e as figurações de deus Hilst organizará sua experiência estética em torno da questão do(s) tempo(s).

\section{Remate final}

Embora se possa falar de temas recorrentes sobre os quais Hilda Hilst se debruça em seus poemas, há um ponto de tensão que atrai e ao mesmo tempo impossibilita um remate final que nos dê um retrato acabado desses mesmos temas. Isso acontece porque os temas (embora sejam o centro gravitacional dos livros) se dispersam e se multiplicam, se 
amalgamam uns aos outros, ao longo dos livros. Por isto, o mais acertado seria falar em núcleos ou feixes temáticos. Hilst não só tece logicamente o tecido do texto poético, mas, numa aparente falta de senso, ao mesmo tempo, em muitos momentos o esgarça.

Muitas vezes, a poeta corta, desvia, ou desoperacionaliza o discurso poético com perguntas, que explicitam a discussão exposta sobre a "irrealidade" do poema, ou do que a linguagem poética cria. Isto faz com que num mesmo poema se ouçam outras vozes que fazem parte da orquestração poética que multiplica os pontos de vista, criando um espelhamento dramático e metalinguístico do texto. Sendo assim, o interlocutor serve como um eu-ausente, cuja função é possibilitar o aparecer, por exemplo, da pergunta sob a máscara da interlocução: "Pulsas como se fossem de carne as borboletas. / E o que vem a ser isso? perguntas. / Digo que assim há de começar o meu poema."viii Ou seja, num mesmo movimento discursivo, Hilst nos dá o direito e o avesso de seu texto, sua camada aparente (de poder encantatório, de beleza da palavra poética), mas também expõe a sua ineficácia lógica, sua inverossimilhança explícita. Esse dado reforça a ideia de que Hilst figura uma cena dramática em sua poesia. E às vezes coloca nela um excedente simbólico fora de cena (obsceno), pela necessidade de alargamento do gesto poético. Quando aparece, este transbordamento significativo é posto em primeiro plano da cena para desautorizar a "verossimilhança" do que se lê nos próprios poemas. Assim, o poema torna-se uma figuração em alta tensão, em curto-circuito, o que alarga os sentidos ao mesmo tempo em que os arruína. Alguns livros de poesia de Hilst, depois de 1974, caminham para este lugar discursivo do trânsito vertiginoso do processo de significação. Neles, o poema é o lugar discursivo no qual se encenam, se figuram as experiências reais ou potenciais. Esta tensão conceitual, sob a qual os poemas se fundam, é o elemento primordial que impossibilita o remate final, o assentamento da significação. Sendo o centro gerador dos contrastes significativos, esta tensão contorna e delimita o fazer poético da escritora como um lugar de passagem, de trânsito. É um estar sempre “entre". Esse dado determina uma dinâmica das trocas simbólicas que se figura ou se atualiza como momento ímpar de tensão representacional. Sendo assim, a poética hilstiana é multifacetada e mutante, tendo como único elemento de fixação de significados o tempo, que é uma amarra conceitual que liga os temas entre si, formando, assim, uma tela, um quadro com paisagem de fundo. Os temas, quase sempre, estarão vinculados, subordinados, à reflexão sobre o tempo, que projeta o poema sobre uma superfície com profundidade, e é sobre essa superfície que os grandes temas da poesia de Hilst são encenados. Temos, assim, um quadro dinâmico que se modifica a cada vez que é visto. Por fim, resta-nos dizer que, em sua poesia madura, Hilda Hilst investe a 
palavra poética de um estatuto de reflexão sobre a própria linguagem poética, e de fuga da linguagem corriqueira. Ela assim o faz porque se confronta obsessivamente com alguns temas, com algumas perguntas recorrentes, com algumas reflexões para as quais não encontra respostas. Isto faz com que a escritora busque constantemente uma linguagem que dê conta de expressar seus pensamentos. Temos dois movimentos paradoxais que alinhavam a definição do que é a linguagem poética hilstiana: de um lado ela se faz para dar conta da proliferação dos questionamentos que a poeta tem, de outro ela desautoriza a si mesma quando reflete sobre a própria verossimilhança da linguagem poética. Sendo assim, os poemas de Hilda Hilst são um pouco de construção, um pouco de ruína.

\section{Referências}

HILST, Hilda. Exercícios. São Paulo: Globo, 2002. . Do desejo. São Paulo: Globo, 2004.

. Da morte. Odes mínimas. São Paulo: Globo, 2003. . Fluxo-floema. São Paulo: Perspectiva, 1970.

PÉCORA, Alcir. "Nota do organizador". In: HILST, Hilda. Exercícios. 1 a ed. São Paulo: Globo, 2002. p. 7-10.

PEDROSO, Braulio. "Hilda Hilst e a poética”. O Estado de São Paulo, São Paulo, 5 ago. 1961, p. 2-3.

RIBEIRO, Leo Gilson. “Os versos de Hilda Hilst, integrando a nossa realidade”. Jornal da Tarde, São Paulo, 14 fev. 1981. p. 3-4.

RIEGER, Angelica. "La dialectique du réel et du poétique chez les trobadours. Les quatre 'protagonistes' de la fin 'amors". In: Revue de langue romanes. Montpellier, Université Paul Valéry, tome LXXXVII, 1983. p. 241-257.

\footnotetext{
${ }^{\text {i }}$ PEDROSO, Braulio. Hilda Hilst e a poética. O Estado de São Paulo, São Paulo, 5 ago. 1961, p. 2-3.

ii HILST, Hilda. Exercícios. São Paulo: Globo, 2002, p. 133.

iii RIBEIRO, Leo Gilson. Os versos de Hilda Hilst, integrando a nossa realidade. Jornal da Tarde, São Paulo, 14 fev. 1981. p. 3.

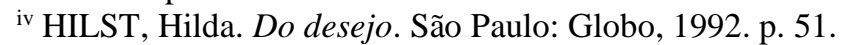

v Livro no qual se encontram 20 poemas inéditos, e Amavisse, Alcoólicas e Sobre a tua grande face, livros de poesia de Hilst já publicados anteriormente.

${ }^{\mathrm{vi}}$ HILST, Hilda. Do desejo. São Paulo: Globo, 2004. p. 16.

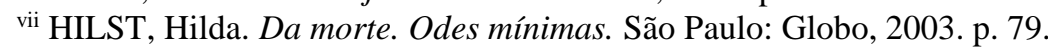

viii HILST, Hilda. Do desejo. São Paulo: Globo, 2004. p. 26.
} 